\title{
AN OSTEOLOGICAL STUDY OF ARCUATE FORAMEN IN ATLAS AND
} ITS CLINICAL SIGNIFICANCE

\author{
Padmalatha $\mathrm{K}^{1}$, Prathap Kumar J *2, Prakash B S ${ }^{3}$, Kalpana Udupa 4. \\ ${ }^{1}$ Associate Professor, ESIC-Medical College \& PGIMSR, Bengaluru, Karnataka, India. \\ ${ }^{* 2}$ Assistant Professor, Ramaiah Medical College, Bengaluru, Karnataka, India. \\ ${ }^{3}$ Professor \& HOD, Hassan Institute of Medical Sciences, Hassan, Karnataka, India. \\ ${ }^{4}$ Intern, ESIC-Medical College \& PGIMSR, Bengaluru, Karnataka, India.
}

\section{ABSTRACT}

Background: Atlas, first cervical vertebra bears sulcus over posterior arch for third part of vertebral artery. Sometimes an osseous bridge converts the sulcus into a foramen called as Arcuate foramen. It is commonly called as Kimmerle's anomaly, also known as Ponticulus Posticus. It is the product of the complete or incomplete ossification of the posterior atlanto-occipital membrane over the vertebral artery groove resulting in the formation of a foramen (Arcuate foramen) containing the vertebral artery and the posterior branch of the C-1 spinal nerve. This variation has been associated with vertebro-basilar insufficiency symptoms, various types of headaches, and acute hearing loss. The knowledge of this variant prevents complications during lateral mass screw fixation, posterior laminectomy and endovascular surgery.

Aims: The aim of the present study was to analyze the percentage of incidence of arcuate foramen and to identify its clinical significance.

Materials and Methods: Hundred dried human atlas bones were used to study the presence of arcuate foramen in the department of Anatomy at ESIC Medical College and PGIMSR, Rajajinagar, Bangalore.

Results: We came across the presence of arcuate foramen in two out of hundred bones. In both the atlas bones, osseous bridge extending from posterior aspect of superior articular facet to the posterior arch of atlas on the left side, forming arcuate foramen, posterior to foramen transversarium was observed.

Conclusion: Arcuate foramen commonly called as Kimmerle's anomaly where in a groove for vertebral artery is converted into a foramen by ossification of the ligament. Awareness of osseous bridging is essential in performing cranio-cervical junction surgeries. It also serves as an anthropological data and also identifying the impact of complete arcuate foramen on the signs and symptoms of vertebra-basilar insufficiency.

KEY WORDS: Arcuate foramen, Kimmerle's anomaly, vertebro-basilar insufficiency, lateral mass screw fixation, posterior laminectomy, endovascular surgery.

Address for Correspondence: Dr Prathap Kumar J, Assistant Professor, Department of Anatomy, Ramaiah Medical College, M S R Nagar, MSRIT post, Mathikere, Bangalore, Karnataka, India- 560054. Phone no: +919743989426 E-Mail: dr.prathapkumar@gmail.com

\begin{tabular}{|c|c|c|c|}
\hline Access this Article online & \multicolumn{3}{|c|}{ Journal Information } \\
\hline \multirow[t]{4}{*}{ Quick Response code } & \multicolumn{3}{|c|}{$\begin{array}{l}\text { International Journal of Anatomy and Research } \\
\text { ISSN (E) 2321-4287 | ISSN (P) 2321-8967 }\end{array}$} \\
\hline & \multicolumn{2}{|c|}{ 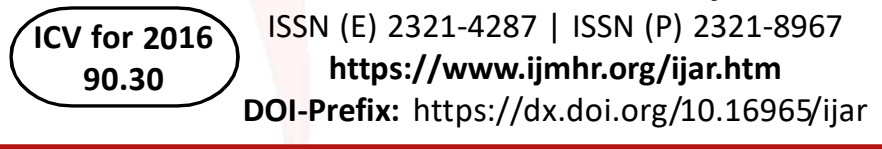 } & $((c)) \mathrm{Er}$ \\
\hline & \multicolumn{3}{|c|}{ Article Information } \\
\hline & \multirow{2}{*}{$\begin{array}{l}\text { Received: } 20 \text { Jun } 2018 \\
\text { Peer Review: } 20 \text { Jun } 2018 \\
\text { Revised: None }\end{array}$} & \multicolumn{2}{|c|}{$\begin{array}{l}\text { Accepted: } 06 \text { Sep } 2018 \\
\text { Published (O): } 05 \text { Nov } 2018\end{array}$} \\
\hline DOI: 10.16965/ijar.2018.329 & & \multicolumn{2}{|c|}{ Published (P): 05 Nov 2018} \\
\hline
\end{tabular}

\section{INTRODUCTION}

Atlas vertebra is named after a greek warrior ATLAS who carries the globe on his head, imilarly atlas bone carries head over it. $s$ Atlas is a unique bone which fails to incorporate a centrum, whose expected position is occupied by dens Atlantoaxial complex represents complex anatomy and biomechanics of thisregion of spine [1]. 
Sulcus arteriae vertebralis which is situated on the cranial surface of posterior arch, occasionally converted into a foramen /canal by a bony arch is known as Arcuate foramen [2].

The partial bony bridge is seen in younger age groups (10-30years) and complete bony bridge usually in older age groups (30-80 years) [3].

\section{MATERIALS AND METHODS}

Hundred dried human atlas bones were studied at ESIC medical college, Rajajinagar, bengaluru for the presence of Arcuate foramen. We came across the presence of arcuate foramen in two out of hundred atlas.

\section{RESULTS}

We came across the presence of Arcuate foramen in two out of hundred bones. The superior view of Atlas -1 showing an osseous bridge extending from posterior aspect of superior articular facet to the posterior arch of atlas on the left side, forming Arcuate foramen, posterior to foramen transversarium [ Figure 1]. The inferior view of atlas -1 [Figure 2] and the lateral view of atlas-1 [Figure 3] are seen.

Fig. 1: Superior surface of Atlas 1 showing Arcuate foramen on left side.

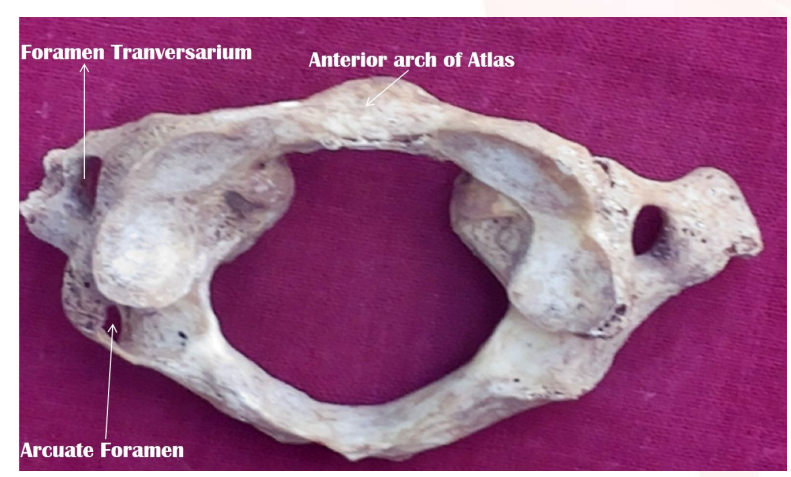

Fig. 2: Inferior surface of Atlas 1 showing Arcuate foramen.

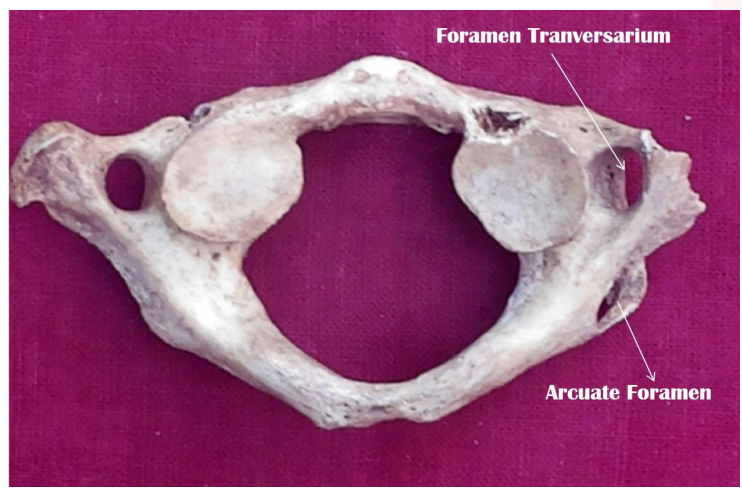

Fig. 3: Lateral surface of Atlas 1 showing Arcuate foramen on left side.

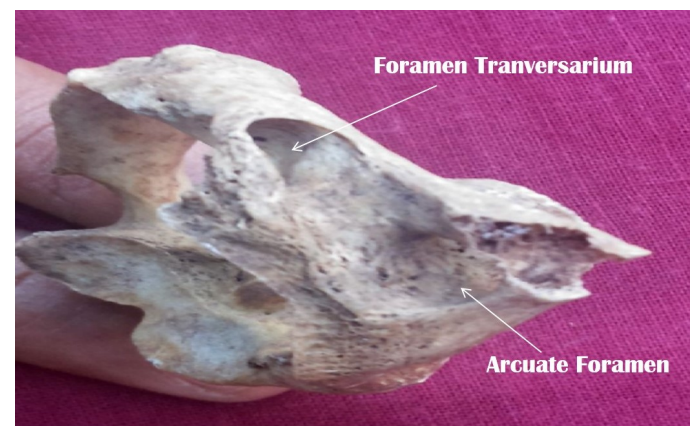

In atlas -2 also, the presence of arcuate foramen posterior to foramen transversarium is seen. The superior view of atlas -2 [Figure 4], the inferior view of atlas -2[Figure 5] and lateral view of atlas-2 [Figure 6] showing the presence of Arcuate foramen are seen. The radiograph of the two atlas bones showing presence of arcuate foramen is seen. [Figure 7].

Fig. 4: Superior surface of Atlas 2 showing Arcuate foramen on left side.

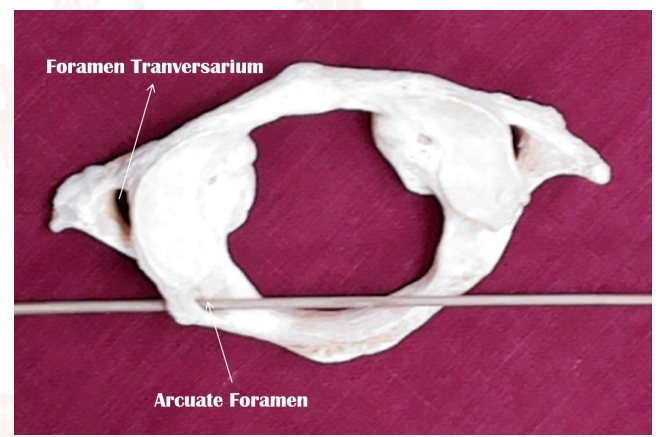

Fig. 5: Inferior surface of Atlas 2 showing Arcuate foramen.

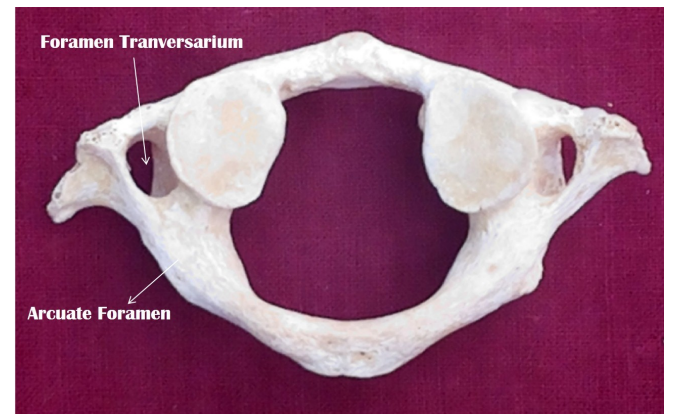

Fig. 6: Lateral surface of Atlas 2 showing Arcuate foramen on left side.

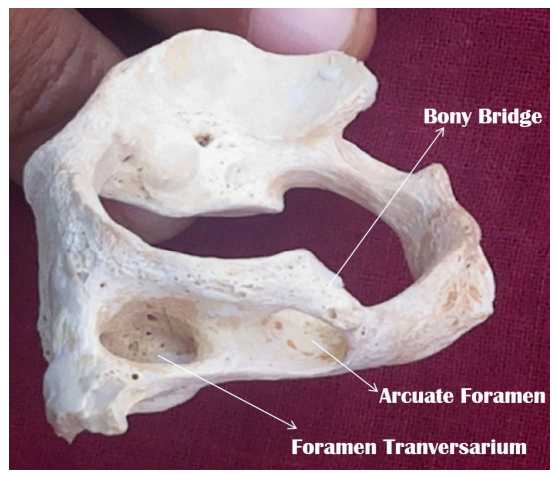


Fig. 7: Radiograph of both Atlas 1 and Atlas 2 showing Arcuate foramen.

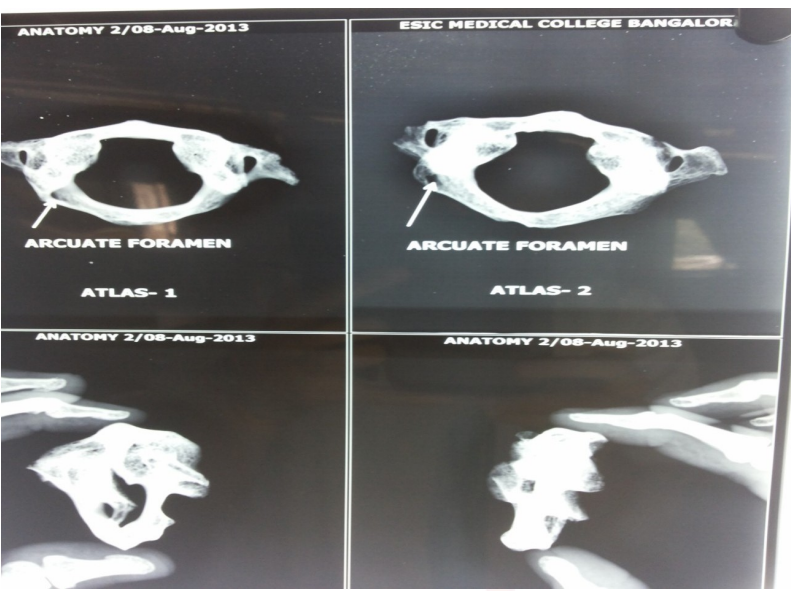

Table 1: Shows the incidence of arcuate foramen by various authors.

\begin{tabular}{|c|c|c|c|}
\hline Name of the author & Year & Material & Incidence\% \\
\hline John Pyo & 1959 & Radiograph & 12.6 \\
\hline Romanus & 1964 & Radiograph & 14.3 \\
\hline Lamberty & 1973 & Bone & 15 \\
\hline Lamberty & 1973 & Radiograph & 7.5 \\
\hline Basaloglo & 1983 & Bone & 9.5 \\
\hline Stubbs & 1991 & Radiograph & 13 \\
\hline Cankur & 1995 & Bone & 14.2 \\
\hline Mitchell & 1998 & Bone & 9.8 \\
\hline Malas & 1998 & Radiograph & 2.6 \\
\hline Mahdi Hasan & 2001 & Bone & 3.4 \\
\hline Erdogan Unur & 2004 & Radiograph & 5.1 \\
\hline Present study & 2017 & Bone & 2 \\
\hline
\end{tabular}

\section{DISCUSSION}

Foramen arcuate has many other names like kimmerle's anomaly/foramen sagittale/foramen atlantoideum/foramen retroarticulare superior/ canalis vertebralis/retrocondylar vertebral artery/atlas bridging/spiculum/ ponticulus posterior of atlas. Arcuate foramen presents migraines and vertebrobasilar artery stroke [4].

Sulcus arteria vertebralis is converted into arcuate foramen which houses vertebral artery, vertebral venous plexus and suboccipital nerve. First description of this foramen done by Kimmerle in the year 1930.Most common in third and fourth decades of life, however documented in children as young as 2 years. The remnants of proatlas, so called occipital vertebra whereas others have suggested they represent ossified ligaments of posterior atlanto-occipital ligament. Arcuate foramen is considered as an anatomical variant which is retrogressive and disappearing morphological phenomenon. It is a direct homologue of superior oblique process in some mammals [5].

In vertebral chain of human fetus, the upper four or five vertebral anlagen fuse to form occipital bone. The most caudal of these are called anteproatlas and proatlas which forms occiput and atlas [6].

The ligaments can ossify completely or incompletely based on which they can be categorized into three groups. Group I represents retroarticular impression on the posterior arch of atlas vertebra. Group II indicates defined retroarticular sulcus and group III represents complete bony ring [7].

Arcuate foramen is considered as a congenital characteristic feature/genetic trait/ossification due to aging. Reports have described this anomaly in relation to posterior cranial fossa strokes and as a possible cause of cervicogenic headache [8].

Arcuate foramen is a retrogressive and disappearing morphological phenomenon. Macalister has asserted that the foramen arcuale is a direct homologue of superior oblique process in some mammals. Tartz and Nathan have stated that the foramen arcuale might be considered as an accessory transverse foramen of atlas [9].

Arcuate foramen is commonly present in quadrupeds or early primates and acts as an additional lateral extension for attachment of posterior atlanto-occipital membrane. In humans, the vertical loading of superior articular process of atlas supports the weight of head; thus roof of tunnel has disappeared. Most important osseous anomaly must be taken into consideration during placement of lateral mass screws into atlas [10].

Kimmerle's anomaly as an anatomic variant can cause a set of clinical symptoms like tension type headaches, vascular headaches and neuralgia. Headaches were accompanied by other complaints like vertigo, and in one third of cases nausea, vomiting, paresthesia, dizziness, short periods of loss of consciousness [11]. Kimmerle's anomaly also manifests as chronic tension type headaches and neurosensory type hearing loss [12].

The Arcuate foramen can present as a complete bone bridge which was seen in 5.2 percent of 
studies whereas partial bridge in 5.8 percent of studies. It may significantly affect the commonly performed C-1 posterior laminectomy [13].

Arcuate foramen limits the normal mobility of the vessel during flexion and extension of the neck and may cause disturbances of arterial flow and of the periarterial sympathetic plexus giving rise to symptoms similar to those found in Barre- Lieou syndrome [14].

The importance of evaluating the grooves and foramina in the region of posterior and lateral margins of atlas and axis in vascular lesions of posterior fossa and in lesions involving cerebellum [15].

Foramen arcuate and along with simultaneous occurrence of fully developed lateral and posterior ponticuli resulting in encasement of the third part of vertebral artery could very likely result in stenosis of vertebral artery [16] The prevalence of arcuate foramen determined by age, gender and degree of calcification [17].

CT angiography study on relations between vertebral artery and atlantoaxial joint. The retroarticular canal has been implicated in compression of vertebral artery, where it passes over the posterior arch of atlas vertebra during extreme rotational movements of head and neck [18].

\section{CONCLUSION}

Arcuate foramen commonly called as Kimmerle's anomaly where in a groove for vertebral artery is converted into a foramen by ossification of the ligament. Awareness of osseous bridging is essential in performing cranio-cervical junction surgeries [19].

However, advancements in engineering and technology have produced an entirely new generation of internal fixation devices that allow for more aggressive surgical intervention for lesions of the atlantoaxial complex. Surgeons have been prompted to reevaluate traditional methods of surgery. Among the new techniques that the surgeons are now implementing are the transcondylar approach, transarticular pillar approach and transarticular screw fixation techniques [2]. Neurosurgeons should consider the presence of foramen arcuale when undertaking endovascular surgery at posterior atlas. Finally, arcuate foramen serves as anthropological data and also identifying the impact of complete arcuate foramen on the signs and symptoms of vertebrobasilar insufficiency.

\section{Conflicts of Interests: None}

\section{REFERENCES}

[1]. Standring S, Ellis H, Healy J.C, Johnson D, Williams A. Gray's Anatomy. The Anatomical basis of clinical practice. $40^{\text {th }}$ edn; Elsevier Churchill livingstone. 2008; 744.

[2]. Pait TG, Arnautovic KI, Borba L.A.B. The Anatomy of the Atlantoaxial Complex. Neurological Surgery; Anatomical Perspectives. 1997;7:91-98.

[3]. Schilling J.J, Schilling A, Caldames I.S. Ponticulus posticus on the posterior arch of atlas, prevalence analysis in asymptomatic patients. Int J Morphol.2010; 28(1): 317-322.

[4]. Huang M.J, Glaser J.A. Complete arcuate foramen precluding $\mathrm{C} 1$ lateral mass screw fixation in a patient with rheumatoid arthritis: case report. lowa orthop. 2003;23:96-99.

[5]. Tubbs R.S, Johnson P.C, Shoja M.M, Loukas M, Oakes W.J. Foramen arcuale: anatomical study and review of literature. Journal of Neurosurgery, Spine. 2007;6: 31-34.

[6]. Straitemeier P.H, Jensen S.R. Partial Regressive Occipital vertebra. Neuroradiology. 1980;19: 47-49.

[7]. Unur E, Erdogan N, Ulger H, Ekinci N, Ozturk O. Radiographic incidence of complete arcute foramen in turkish population. Erciyes Medical Journal. 2004;26(2):50-54.

[8]. Hasan M, Shukla S, Siddiqui M.S, Singh D. Posterolateral tunnels and ponticuli in human atlas vertebrae. J Anatomy.2001;199:339-343.

[9]. Prakash B.S, Padmalatha K, Mamatha Y, Ramesh B.R. Left arteriae vertebralis canal in atlas -Kimmerle anomaly. International Journal of Anatomic Variations (2010);3: 130-131.

[10]. Jason P, Young BS, Paul H, Young MD, Michael J. The Ponticulus posticus: Implications for screw insertion into the first cervical lateral mass. The Journal of Bone \& Joint Surgery.2005; 87(11): 2495-98.

[11].Lekarskie W. Clinical symptoms and signs in kimmerle anomaly. 2002;55(7-8):416-422.

[12]. Koutsourarki E, Avdelidi E, Michmizos D, Kapsali SE, CostaV, Baloyannis S. Kimmerle's anomaly as a possible causative factor of chronic tension -type headaches and neurosensory hearing loss: case report and literature review.Int J Neuroscience. 2010; 120 (3): 236-9.

[13]. Mehmet S, Yakup G, Zafer Y.K, Murat U, Mustafa C, Davut $\mathrm{O}$. The effect of posterior bridging of $\mathrm{C}-1$ on craniovertebral junction surgery. J of Neurosurgery. Spine 2006;5(1); 50-52.

[14]. Limousin C.A. Foramen arcuale and syndrome of barre-lieou; International Orthopaedics.1980;4:4749 . 
[15]. Pyo J, Lowman R.M. The "Ponticulus Posticus" of the first cervical vertebra;Radiology.1959; 72:850-854.

[16].Tubbs S, Shoja MM, Shokouhi G, Farahani RM, Loukas M, Oakes JW.Simultaneous lateral and posterior ponticles resulting in the formation of a vertebral artery tunnelof the atlas;case report and review of literature. Folia Neuropathologica. 2007; 45(1); 43-46.

[17]. Robert A, Cederberg, ByronW, Martha B, English ND. Arcuate foramen: Prevalance by age, gender and degree of calcification. Clinical Orthodontics \&Research. 2008;3(3):162-167.
[18]. Shao-Mao, Feng YE, Qing-chi L, Lia-bin C, Shao-yin D.Three dimensional CT angiography study on the relations between the vertebral artery and atlantoaxial joint. Chinese Medical Journal 2009:122 (8):917-920.

[19]. Simsek S, Yigitkanli K, Comert A, Acar HI, Seckin H. Neuroanatomical study posterior osseous bridging of C1. J of Clinical Neurosciences .2008; 15(6):686-88.

\author{
How to cite this article: \\ Padmalatha K, Prathap Kumar J, Prakash B S, Kalpana Udupa. AN \\ OSTEOLOGICAL STUDY OF ARCUATE FORAMEN IN ATLAS AND \\ ITS CLINICAL SIGNIFICANCE. Int J Anat Res 2018;6(4.2):5835-5839. \\ DOI: 10.16965/ijar.2018.329
}

